\title{
High oxide ion and proton conductivity in a disordered hexagonal perovskite
}

S. Fop ${ }^{\dagger}$, K. S. McCombie ${ }^{\dagger}$, E. J. Wildman ${ }^{\dagger}$, J. M. S. Skakle ${ }^{\dagger}$, J. T. S. Irvine ${ }^{\ddagger}$, P. A. Connor ${ }^{\ddagger}$, C. Savaniu ${ }^{\ddagger}$, C. Ritter ${ }^{\S}$ and A. C. Mclaughlin ${ }^{\dagger}$

† Department of Chemistry, University of Aberdeen, Meston Walk, Aberdeen AB24 3UE, United Kingdom.

¥School of Chemistry, University of St Andrews, St Andrews, Fife KY16 9ST, UK.

$\S$ Institut Laue Langevin, 71 Avenue des Martyrs, BP 156, F-38042 Grenoble Cedex 9, France.

\begin{abstract}
Oxide ion and proton conductors, which exhibit high conductivity at intermediate temperature, are necessary to improve the performance of ceramic fuel cells. The crystal structure plays a pivotal role in defining the ionic conduction properties and the discovery of new materials is a challenging research focus. Here we show that the undoped hexagonal perovskite $\mathrm{Ba}_{7} \mathrm{Nb}_{4} \mathrm{MoO}_{20}$ supports pure ionic conduction with high proton and oxide ion conductivity at $510{ }^{\circ} \mathrm{C}$ (the bulk conductivity is $4.0 \mathrm{mS} \mathrm{cm}-1$ ) and hence is an exceptional candidate for application as a dual-ion solid electrolyte in a ceramic fuel cell which will combine the advantages of both oxide ion and proton conducting electrolytes. $\mathrm{Ba}_{7} \mathrm{Nb}_{4} \mathrm{MoO}_{20}$ also showcases excellent chemical and electrical stability. Hexagonal perovskites form an important new family of materials for obtaining novel ionic conductors with potential applications in a range of energy-related technologies.
\end{abstract}


Interest in oxide-ion and proton-conducting materials has grown recently due to their application as electrolytes in solid-oxide fuel cells (SOFCs) and proton ceramic fuel cells (PCFCs). Fuel cells offer a viable option to produce clean energy from sustainable resources, with low emission of pollutants and high energy conversion rates ${ }^{1,2}$. The majority of commercially available SOFCs use state of the art yttria stabilised zirconia (YSZ) electrolytes. However, YSZ shows adequate conductivities only at high working temperatures $\left(>700{ }^{\circ} \mathrm{C}\right)$, which poses technical challenges in terms of material selections and long-term durability, thus limiting the widespread application of SOFC technology 2, 3, 4 . Development of alternative electrolyte materials possessing good ionic conduction at intermediate temperatures (300 $600^{\circ} \mathrm{C}$ ) has led to the discovery of high oxide ion conductivity in several structural families ${ }^{5}$, $6,7,8,9,10,11,12$. High temperature proton conduction has been reported in doped barium cerates and zirconates, perovskite-related oxides, gallates and acceptor-doped orthoniobates and orthotantalates, which show proton conductivity when exposed to water vapour or hydrogen-rich atmospheres 10,13,14, 15, 16. These materials are attracting considerable attention, with demonstrations of PCFCs capable of generating high power outputs $2,17,18$. However, many proton-conducting oxides suffer from poor chemical stability under $\mathrm{CO}_{2}, \mathrm{H}_{2} \mathrm{O}$ or reducing atmospheres $14,19,20,21,22,23$, and also have low sinterability, thus requiring very high processing temperatures $\left(\sim 1700^{\circ} \mathrm{C}\right) 14,24$. Recently, materials with dual-ion proton and oxide ion conductivity have been proposed as a new class of electrolyte for intermediate temperature fuel cells, as they exhibit low ohmic resistance without external gas humidification 25,26 .

We have explored the hexagonal perovskite structural family in search of novel ionicconducting materials. The perovskite structure is generally composed of a framework of corner-sharing octahedral units. However, if there is a large difference in size between the constituent cations, the octahedral units share faces, thus leading to the formation of hexagonal perovskites. Mixed combinations of corner-sharing and face-sharing octahedra can give rise to a variety of hexagonal perovskite derivatives able to accommodate cationic and anionic vacancies ${ }^{27,}{ }^{28}$. We have discovered significant oxide ion conductivity in $\mathrm{Ba}_{3} \mathrm{NbMO}_{8.5}$ $(M=M o, W)$, which exhibits a hybrid average structure intermediate between the $9 \mathrm{R}$ perovskite and palmierite structures ${ }^{29,}{ }^{30}$. Based on such findings, we have investigated the electrical and structural properties of $\mathrm{Ba}_{7} \mathrm{Nb}_{4} \mathrm{MoO}_{20}$, a cation-deficient $7 \mathrm{H}$ hexagonal perovskite derivative formed by an intergrowth of palmierite layers and $12 \mathrm{R}$ perovskite 
blocks ${ }^{31}$. Here we report that this system supports remarkable oxide ion and proton conductivity with excellent chemical and electrical stability over a range of $\mathrm{pO}_{2}$. The ionic conduction properties of $\mathrm{Ba}_{7} \mathrm{Nb}_{4} \mathrm{MoO}_{20}$ are linked to its distinct disordered crystal structure. These results further demonstrate that cation-deficient hexagonal perovskite derivatives can open up new horizons in the design of novel ionic conductors.

A single-phase material with nominal composition $\mathrm{Ba}_{7} \mathrm{Nb}_{4} \mathrm{MoO}_{20}$ was obtained by conventional solid-state reaction at $1050{ }^{\circ} \mathrm{C}$ for $48 \mathrm{~h}$ (Supplementary Information S1.1 and $\mathrm{S} 1.2)$. Annealing tests under different atmospheres demonstrate that the $\mathrm{Ba}_{7} \mathrm{Nb}_{4} \mathrm{MoO}_{20}$ phase is stable under reducing conditions and after heating in in pure $\mathrm{CO}_{2}(1 \mathrm{~atm})$ between $400{ }^{\circ} \mathrm{C}$ and $600{ }^{\circ} \mathrm{C}$ (Supplementary Information S3).

The electrical properties of a dense ( $~ 95 \%$ of the theoretical neutron diffraction density) $\mathrm{Ba}_{7} \mathrm{Nb}_{4} \mathrm{MoO}_{20}$ pellet were measured under dry air by $\mathrm{AC}$ impedance spectroscopy. Typical complex impedance plots show a small high-frequency bulk arc (capacitance values of $\sim 7-$ $10 \mathrm{pF} \mathrm{cm}-1$ ) and a depressed grain boundary signal (capacitance of $\sim 0.10-0.30 \mathrm{nF} \mathrm{cm}{ }^{-1}$ ) at intermediate frequencies, together with a pronounced electrode response at lower frequencies (Figure 1a and Supplementary Figure S9). The presence of such an electrode signal in the low-frequency region is indicative of ionic conduction in a material with partially blocking electrodes ${ }^{32}$. Equivalent circuit analysis was utilised to extract the individual bulk, grain boundary and electrode responses; a detailed description of the analysis can be found in Supplementary Information S5.3 and S5.4. 
a

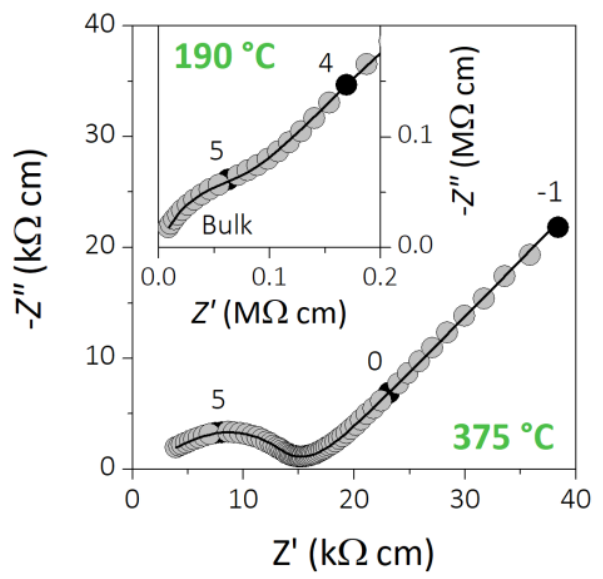

C

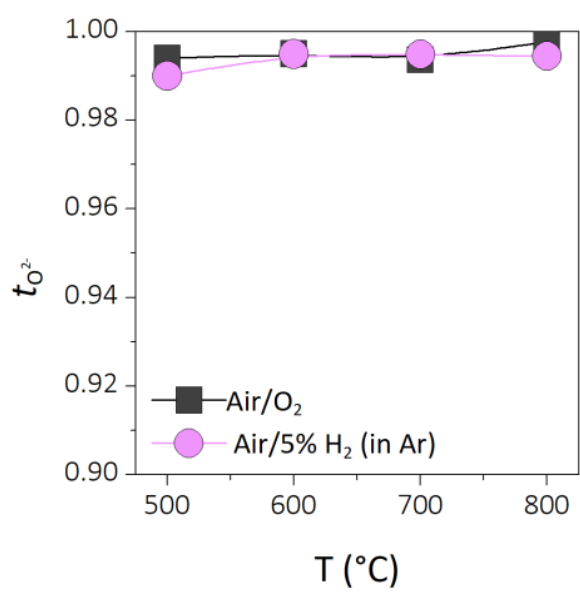

b

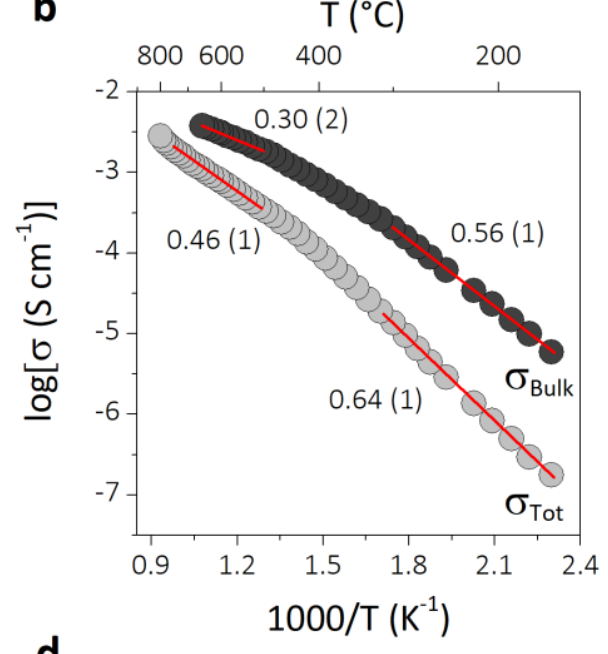

d

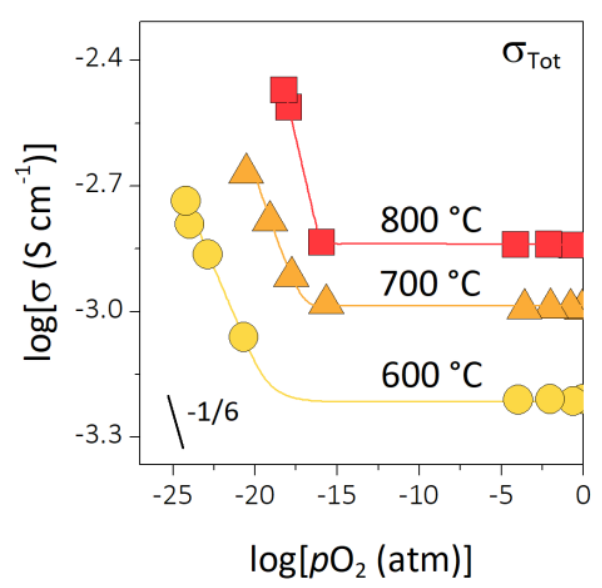

Figure 1. Oxide ion conductivity of $\mathrm{Ba}_{7} \mathrm{Nb}_{4} \mathrm{MoO}_{20}$. a Complex impedance plot recorded in dry air $\left(\mathrm{pH}_{2} \mathrm{O}<10^{-4} \mathrm{~atm}\right)$ at $375^{\circ} \mathrm{C}$, with the inset showing a magnification of the high-frequency bulk signal for the data collected at $190{ }^{\circ} \mathrm{C}$. The numbers and corresponding filled circles indicate selected frequency decades; the black line is the equivalent circuit fitting. $\mathbf{b}$ Arrhenius plot of the bulk and total conductivity in dry air; activation energies are reported (in eV). c Oxygen transport number over the temperature range $500-800{ }^{\circ} \mathrm{C}$ measured with the concentration cell method. $\mathbf{d}$ Dependence of the total conductivity vs $\mathrm{pO}_{2}$.

An Arrhenius plot of the total and bulk conductivity of $\mathrm{Ba}_{7} \mathrm{Nb}_{4} \mathrm{MoO}_{20}$ measured in dry air is presented in Figure 1b. Electromotive force (EMF) measurements at selected temperatures between $500{ }^{\circ} \mathrm{C}$ and $800^{\circ} \mathrm{C}$ confirm the presence of oxide ion conduction. Oxide ion transport numbers, $t_{\mathrm{O}^{2-}}$, of $>0.99$ were obtained in both air $/ \mathrm{O}_{2}$ and air $/ 5 \% \mathrm{H}_{2}$ (in $\mathrm{Ar}$ ), indicating that $\mathrm{Ba}_{7} \mathrm{Nb}_{4} \mathrm{MoO}_{20}$ is an oxide ion conductor with negligible electronic conductivity (Figure 1c). Conductivity measurements against partial pressure of oxygen, $p \mathrm{O}_{2}$, indicate that the electrolytic domain of $\mathrm{Ba}_{7} \mathrm{Nb}_{4} \mathrm{MoO}_{20}$ extends between $\sim 10^{-18}-1$ atm at $600{ }^{\circ} \mathrm{C}$, narrowing to $10^{-16}-1 \mathrm{~atm}$ at $700{ }^{\circ} \mathrm{C}$ and $800{ }^{\circ} \mathrm{C}$ (Figure $1 \mathrm{~d}$ ). At the lowest oxygen partial pressures, an 
increase in the total conductivity is evidenced suggesting that $n$-type electronic conductivity is observed at low $\mathrm{pO}_{2}$ values, analogously to $\mathrm{Ba}_{3} \mathrm{NbMoO}_{8.5}{ }^{29}$. The value of the oxygen transport number $(\sim 0.99)$ and the presence of clear Warburg/electrode responses at all temperatures in the complex impedance plots recorded in reducing $5 \% \mathrm{H}_{2}$ (in $\mathrm{N}_{2}$ ) (Supplementary Figure S13) however suggest that the electronic component in $\mathrm{Ba}_{7} \mathrm{Nb}_{4} \mathrm{MoO}_{20}$ is small and the conductivity is predominantly ionic.

Impedance spectroscopy measurements were also performed in air $+\mathrm{H}_{2} \mathrm{O}$ (humidified air). The complex impedance plots show the high-frequency bulk arc only at low temperatures (Figure 2a). A prominent Warburg spike signal is visible at low frequencies at all temperatures (Figure $2 \mathrm{~b}$ and Supplementary Figure S10). The Arrhenius plot in Figure $2 \mathrm{c}$ reveals a significant increase in the total conductivity in air $+\mathrm{H}_{2} \mathrm{O}$ above $\sim 300{ }^{\circ} \mathrm{C}$, suggesting proton conduction. Such an increase in conductivity is also evidenced by the figure showing the relative increase in conductivity in humidified air against the temperature (Supplementary Figure S18). The presence of proton conduction is further corroborated by impedance spectroscopy measurements in air $+\mathrm{D}_{2} \mathrm{O}$, which clearly show a reduction in conductivity due to the isotope effect (Figure 2d). The resistivity in air $+\mathrm{D}_{2} \mathrm{O}$ is $\sim 1.3-1.4$ times higher than in air $+\mathrm{H}_{2} \mathrm{O}$ above $300{ }^{\circ} \mathrm{C}$ (Supplementary Figure S20). Proton bulk conductivities were extracted from complex impedance data collected in air $+\mathrm{H}_{2} \mathrm{O}$ following equivalent circuit analysis (Supplementary Information S5.4). The Arrhenius plot in Figure 2c shows that the bulk activation energy is $0.57 \pm 0.04 \mathrm{eV}$ in the low temperature region and gradually decreases above $\sim 300{ }^{\circ} \mathrm{C}$. The bulk conductivity of $\mathrm{Ba}_{7} \mathrm{Nb}_{4} \mathrm{MoO}_{20}$ in air $+\mathrm{H}_{2} \mathrm{O}\left(4.0 \mathrm{mS} \mathrm{cm}-1\right.$ at $\left.510{ }^{\circ} \mathrm{C}\right)$ is higher than the bulk conductivity measured in dry air $\left(1.9 \mathrm{mS} \mathrm{cm}^{-1}\right.$ at $\left.510{ }^{\circ} \mathrm{C}\right)$. These results demonstrate that $\mathrm{Ba}_{7} \mathrm{Nb}_{4} \mathrm{MoO}_{20}$ shows significant proton conduction. 
a
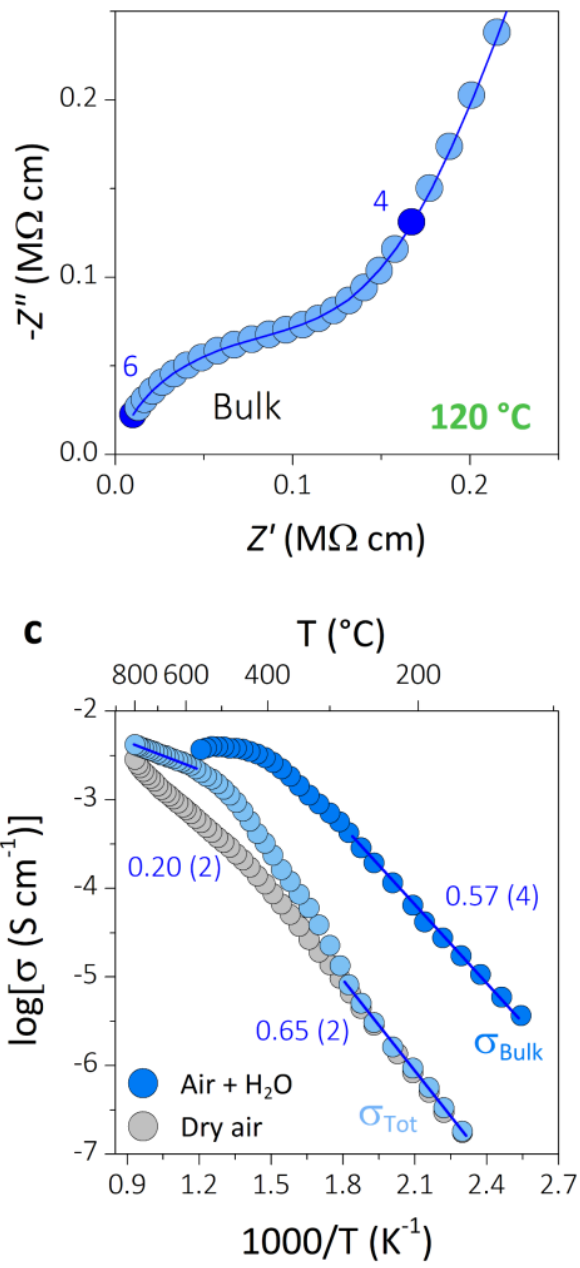

b

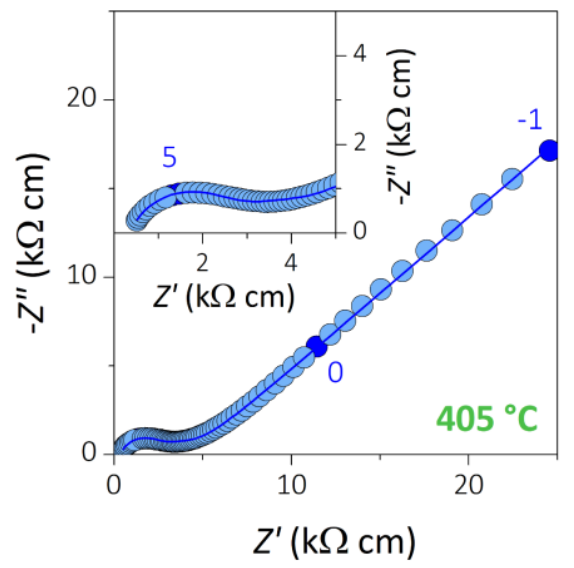

d

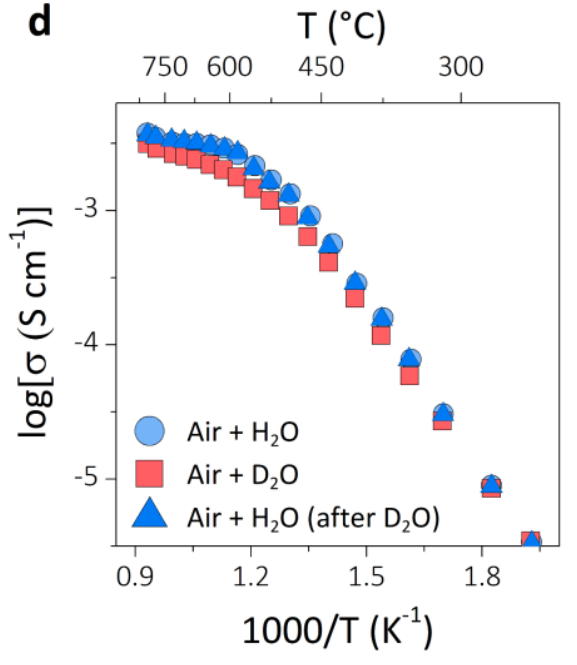

Figure 2. Proton conductivity in $\mathrm{Ba}_{7} \mathrm{Nb}_{4} \mathrm{MoO}_{20}$ under humidified conditions $\left(p \mathrm{H}_{2} \mathrm{O} \sim 0.021\right.$ atm). a, b Complex impedance plots of $\mathrm{Ba}_{7} \mathrm{MoNb}_{4} \mathrm{O}_{20}$ recorded in air $+\mathrm{H}_{2} \mathrm{O}$ at $120^{\circ} \mathrm{C}$ and 405 ${ }^{\circ} \mathrm{C}$. Magnification of the high-frequency bulk signal at $120^{\circ} \mathrm{C}$ is shown in $\mathrm{a}$. The numbers and corresponding filled circles in $\mathbf{a}, \mathbf{b}$ indicate selected frequency decades; the blue line is the equivalent circuit fitting. c, d Arrhenius plots of the conductivity of $\mathrm{Ba}_{7} \mathrm{MoNb}_{4} \mathrm{O}_{20}$ in humidified air atmosphere. The bulk and total conductivities, with the respective activation energies (in eV), in air $+\mathrm{H}_{2} \mathrm{O}$ are compared with the total conductivity in dry air in c. Reduction of the total conductivity in air $+\mathrm{D}_{2} \mathrm{O}$ due to the isotope effect is shown in the Arrhenius plot in $\mathbf{d}$. 


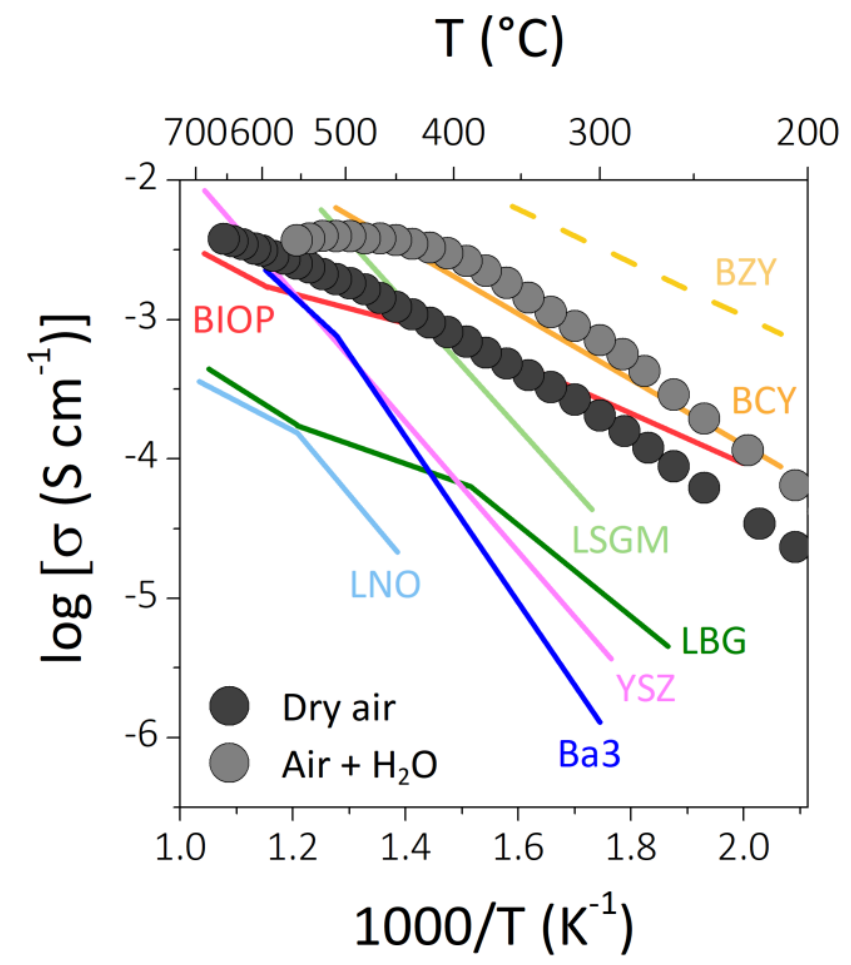

Figure 3. Comparison of the bulk conductivity of $\mathrm{Ba}_{7} \mathrm{Nb}_{4} \mathrm{MoO}_{20}$ with other leading ionic conductors. The bulk conductivity of $\mathrm{Ba}_{7} \mathrm{MoNb}_{4} \mathrm{O}_{20}$ in dry air and air $+\mathrm{H}_{2} \mathrm{O}\left(p \mathrm{H}_{2} \mathrm{O} \sim 0.021\right.$ atm) is compared with the conductivities of $\mathrm{Zr}_{0.92} \mathrm{Y}_{0.08} \mathrm{O}_{1.96}$ (YSZ) (ref. 4), $\mathrm{La}_{0.8} \mathrm{Sr}_{0.2} \mathrm{Ga}_{0.83} \mathrm{Mg}_{0.17} \mathrm{O}_{2.815}$ (LSGM) (ref. 6), $\mathrm{Ba}_{3} \mathrm{MoNbO}_{8.5}$ (Ba3) (ref. 29), La0.8 $\mathrm{Ba}_{1.2} \mathrm{GaO}_{3.9}$ (LBG) (ref. 10), $\mathrm{Ba}_{2} \mathrm{In}_{1.7} \mathrm{P}_{0.3} \mathrm{O}_{5.3}$ (BIOP) (ref. 8), $\mathrm{La}_{0.99} \mathrm{Ca}_{0.01} \mathrm{NbO}_{4}$ (LNO) (ref. 16), $\mathrm{BaCe}_{0.9} \mathrm{Y}_{0.1} \mathrm{O}_{-\delta}$ $(\mathrm{BCY})$ and the extrapolated bulk conductivity data of $\mathrm{BaZr}_{0.8} \mathrm{Y}_{0.2} \mathrm{O}_{3-\delta}$ (BZY) (both from ref. 13).

The Arrhenius plot in Figure 3 shows that the bulk conductivity of $\mathrm{Ba}_{7} \mathrm{Nb}_{4} \mathrm{MoO}_{20}$ is significantly higher than the conductivity of $\mathrm{Zr}_{0.92} \mathrm{Y}_{0.08} \mathrm{O}_{1.96}$ (YSZ) 4 and comparable to $\mathrm{La}_{0.8} \mathrm{Sr}_{0.2} \mathrm{Ga}_{0.83} \mathrm{Mg}_{0.17} \mathrm{O}_{2.815}(\mathrm{LSGM})^{6}$. In addition, the bulk conductivity in air $+\mathrm{H}_{2} \mathrm{O}$ is about two orders of magnitude higher than the conductivity of $\mathrm{La}_{0.99} \mathrm{Ca}_{0.01} \mathrm{NbO}_{4}(\mathrm{LNO}){ }^{16}$, and compares very well with the conductivities of both Y-doped barium cerate and zirconate ${ }^{13}$. $\mathrm{Ba}_{7} \mathrm{Nb}_{4} \mathrm{MoO}_{20}$ is currently undoped so that targeted chemical doping should further enhance the oxide ion or proton conductivity.

Garcia-González et al. described the structure of $\mathrm{Ba}_{7} \mathrm{Nb}_{4} \mathrm{MoO}_{20}$ as a $7 \mathrm{H}$ hexagonal perovskite composed by an ordered intergrowth of the $12 \mathrm{R}$ perovskite and palmierite units, interspaced by a plane of empty cationic sites ${ }^{31}$. This structure was employed as a starting model for Rietveld refinement. Large thermal displacement parameters were obtained for the apical tetrahedral oxygen atom 01 within the palmierite layers, clearly suggesting oxygen disorder on the $a b$ plane, as previously evidenced ${ }^{31}$. Examination of difference Fourier maps at $50{ }^{\circ} \mathrm{C}$ 
showed significant missing nuclear scattering density in proximity of the $\mathrm{O} 1$ site, at Wyckoff position $3 e(1 / 2,0,0)$ (Figure $4 a)$. An oxygen atom was added at position $3 e(02)$, which resulted in more realistic thermal displacement values of the highly disordered $\mathrm{O} 1$ site. Missing nuclear scattering density also revealed an additional metal atom $(\mathrm{M} 2)$ at $2 d(1 / 3,2 / 3, \sim 0.19)$ (Supplementary Figure S26). The Rietveld fit to this model (Figure 4b) resulted in excellent agreement between the calculated and observed patterns (Supplementary Figure S27), with good statistical factors and realistic atomic displacement parameters for all atoms (Table S2). Additional details about the Rietveld analysis can be found in Supplementary Information S9. The short 01-02 distance (maximum 2.0 A) does not allow simultaneous occupation of the two oxygen sites. The $\mathrm{O} 1$ and $\mathrm{O} 2$ sites are therefore partially occupied, leading to mixed coordination of the $d$-metal atoms (M1) along the palmierite-like layers. Arrangement of the oxygen ions on two average oxygen sites indicates the creation of a random distribution of $\mathrm{M} 1 \mathrm{O}_{4}$ tetrahedral $(\mathrm{O} 1)$ and ${\mathrm{M} 1 \mathrm{O}_{6}}_{6}$ octahedral (O2) units in the average crystal structure. However, the proximity and accessibility of the two oxygen sites suggests considerable positional disorder of the oxide ions on the palmierite-like layers, producing a range of $\mathrm{M} 1 \mathrm{O}_{\mathrm{x}}$ polyhedral units with variable local geometries. Neutron pair distribution function analysis has indeed highlighted the existence of mixed 4-, 5-, and 6-fold local coordination environments within the palmierite-like layers of the related $\mathrm{Ba}_{3} \mathrm{NbMoO}_{8.5}$ phase ${ }^{33}$. The $\mathrm{M} 1$ and M2 sites are also partially occupied. The cation vacancies are distributed on the M1 and M2 sites, resulting in four possible local stacking configurations as shown in Figure 4c. 
a

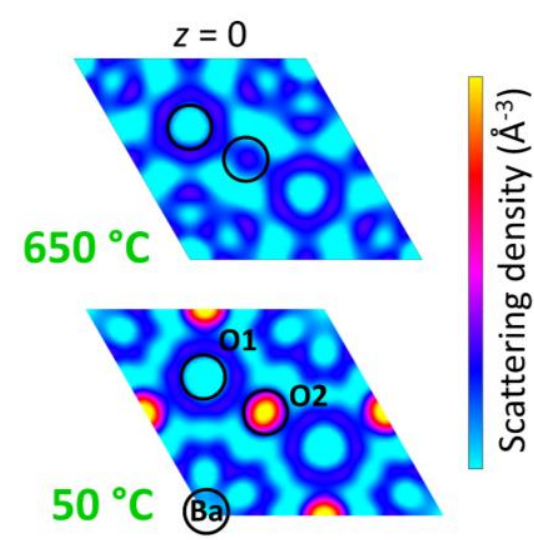

C

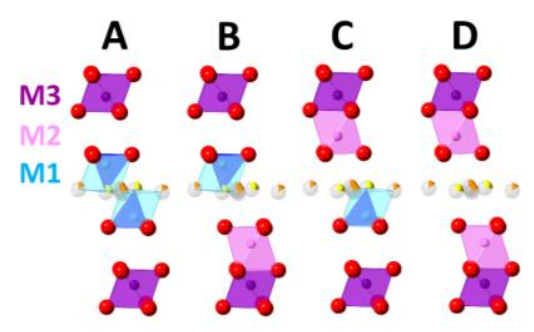

b

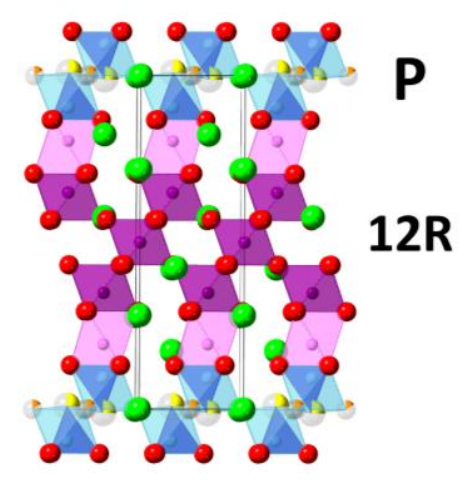

d

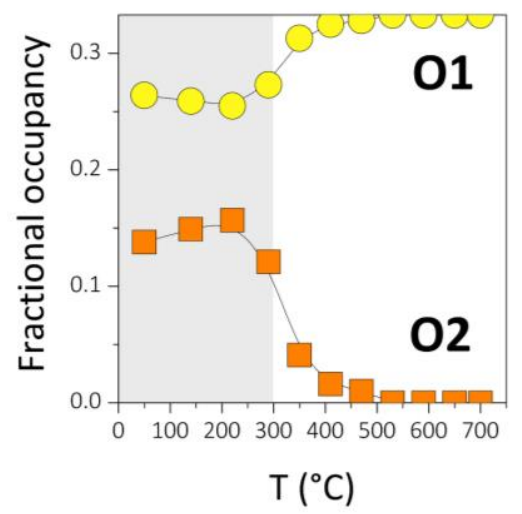

Figure 4. The crystal structure of $\mathrm{Ba}_{7} \mathrm{Nb}_{4} \mathrm{MoO}_{20}$ and thermal rearrangement of the oxygen fractional occupancies. a Difference Fourier maps at $z=0$ seen along the [001] direction. The map at $50^{\circ} \mathrm{C}$ shows occupation of the extra oxygen site, 02 . There is no significant residual scattering density at $\mathrm{O} 2$ above $500{ }^{\circ} \mathrm{C}$, evidencing that the site is on average unoccupied at high temperatures. b Average crystal structure of $\mathrm{Ba}_{7} \mathrm{Nb}_{4} \mathrm{MoO}_{20}$ composed by alternating palmierite-like and 12R perovskite layers. $\mathrm{O} 1$ and $\mathrm{O} 2$ sites are partially occupied, leading to variable coordination of the $\mathrm{M} 1$ cations along the palmierite-like layers. Partial occupation of $\mathrm{M} 1$ and $\mathrm{M} 2$ sites evidences disorder of the cationic vacancies. Colours indicate the following: light green, Ba; blue/cyan, M1; magenta, M2; purple, M3 and M4; yellow, O1; orange, O2; red, 03, 04 and 05. The split 01 position is not shown for simplicity. c Possible local configurations due to arrangement of the cationic vacancies on the $M 1$ and $M 2$ sites. $A$ : the presence of cationic vacancies on the $\mathrm{M} 2$ sites only leads to the ordered palmierite - $12 \mathrm{R}$ perovskite stacking; $B$ and $C$ : vacancies are distributed on both metal positions giving alternated layers of occupied-unoccupied $\mathrm{M} 1$ and $\mathrm{M} 2$ sites; $\mathrm{C}$ : vacancies on the $\mathrm{M} 1$ site only result in an unfavourable configuration. $\mathbf{d}$ Variation of the $\mathrm{O} 1$ and $\mathrm{O} 2$ fractional occupancies with the temperature. There is a redistribution of the oxygen occupancies in favour of the $\mathrm{O} 1$ site above $300^{\circ} \mathrm{C}$, also evidenced by the difference Fourier maps.

The various configurations will be randomly distributed along the structural layers, thus creating complex disordered arrangements of the cationic vacancies resulting in disruption of 
the average ordered stacking of palmierite and $12 \mathrm{R}$ perovskite units on the local scale. Disorder of the cationic sub-lattice has also been reported in $\mathrm{Ba}_{3} \mathrm{NbMO}_{8.5}{ }^{34}$.

Rietveld refinement evidences a thermal reorganisation of the oxygen fractional occupancies at the $\mathrm{O} 1$ and $\mathrm{O} 2$ sites. The $\mathrm{O} 1$ fractional occupancy increases upon heating above $290{ }^{\circ} \mathrm{C}$, while the fractional occupancy of $\mathrm{O} 2$ decreases (Figure 4d). A change in slope of the unit cell parameters is also observed at $290{ }^{\circ} \mathrm{C}$ (the $a$-axis presents a thermal expansion coefficient of $11.4(3) \times 10^{-6}{ }^{\circ} \mathrm{C}^{-1}$ below $290{ }^{\circ} \mathrm{C}$, and $15.4(2) \times 10^{-6}{ }^{\circ} \mathrm{C}^{-1}$ above $290{ }^{\circ} \mathrm{C}$; the values for the $\mathrm{c}$-axis are $7.07(1) \times 10^{-6}{ }^{\circ} \mathrm{C}^{-1}$ and $12.0(3) \times 10^{-6}{ }^{\circ} \mathrm{C}^{-1}$ ) (Supplementary Figure S30). Above $500{ }^{\circ} \mathrm{C}$, the $\mathrm{O} 1$ site is fully occupied, while $\mathrm{O} 2$ is empty. Difference Fourier maps calculated with the occupancy of $\mathrm{O} 2$ set to zero show no significant residual scattering density at the $3 e$ Wyckoff position (the Fourier difference map at $650{ }^{\circ} \mathrm{C}$ is shown in Figure 4a), evidencing that the $\mathrm{O} 2$ site is on average unoccupied above $500{ }^{\circ} \mathrm{C}$.

The partially occupied oxygen sites and the intrinsic vacancies along the palmierite-like layers provide viable oxide ion migration pathways and allow the formation and diffusion of protonic (hydroxyl) defects from the dissociative absorption of water $\left(\mathrm{H}_{2} \mathrm{O}_{(\mathrm{g})}+\mathrm{V}_{\mathrm{O}}^{\bullet}+\mathrm{O}_{\mathrm{o}}^{\mathrm{X}} \leftrightarrow 2 \mathrm{OH}_{0}^{\bullet}\right)$. Rearrangement of the oxygen fractional occupancies and analysis of Fourier maps strongly suggest oxygen interchange between $\mathrm{O} 1$ and $\mathrm{O} 2$ sites, revealing oxide ion migration over the O2-02-O2 face of the $\mathrm{M} 10_{6}$ pseudo-octahedron through the $\mathrm{O} 1$ sites, assisted by facile reorganisation of the coordination of the $\mathrm{M} \mathrm{O}_{x}$ units, as identified in $\mathrm{Ba}_{3} \mathrm{NbMoO}_{8.5}{ }^{35}$. This mechanism considerably differs from the one found for $\mathrm{AMO}_{3}$ perovskite oxides, where oxygen diffusion follows a curved trajectory along the edge of the $\mathrm{MO}_{6}$ octahedron ${ }^{36}$. The broad and almost continuous distribution of accessible oxygen sites and the variability of the

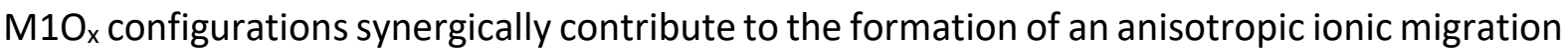
pathway along the palmierite-like layers. In hexagonal $\mathrm{Ba}_{7} \mathrm{Nb}_{4} \mathrm{MoO}_{20}$, low-energy proton transport is enabled by the proximity of available oxygen sites and the considerable flexibility

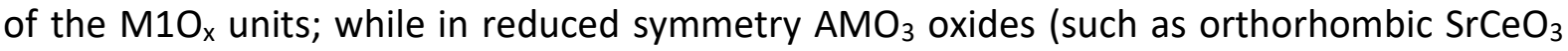
and $\left.\mathrm{CaZrO}_{3}\right)$ an extra enthalpy contribution is needed for tilting of two adjacent octahedra closer enough to allow proton hopping ${ }^{13,36}$.

The thermal reorganisation of the vacancy distribution and average oxide ion positions in favour of the $\mathrm{O} 1$ tetrahedral site strongly influences the ionic conduction. There is a decrease in the activation energy values for oxide ion diffusion in correlation with the structural change. The Arrhenius plot of the bulk conductivity shows a gradual reduction of the 
activation energy $\left(E_{\mathrm{a}}\right)$ above $300^{\circ} \mathrm{C}$; from $0.56 \pm 0.01 \mathrm{eV}$ in the low temperature region (160 $-300{ }^{\circ} \mathrm{C}$ ) to $0.30 \pm 0.02 \mathrm{eV}$ in the high temperature region $\left(500-655^{\circ} \mathrm{C}\right)$ (Figure $\left.1 \mathrm{~b}\right)$. In addition, the proton conductivity increases in humidified air above $\sim 300^{\circ} \mathrm{C}$, simultaneously with the structural reorganisation (Supplementary Figure S18). A simple estimate of the protonic transport number, $t_{\mathrm{H}}$, based on the total conductivity values in dry and humidified atmospheres 15 shows a considerable increase of the protonic contribution at the temperature at which the change in 01/02 fractional occupancies occurs (Supplementary Figure S22). The calculated proton transport number steeply increases above $\sim 300{ }^{\circ} \mathrm{C}$, reaching a value of $\sim 0.81$ at $525{ }^{\circ} \mathrm{C}$. This trend is further confirmed by the temperature variation of the $R\left(D_{2} \mathrm{O}\right) / R\left(\mathrm{H}_{2} \mathrm{O}\right)$ ratio obtained from measurement of the isotope effect in air $+\mathrm{D}_{2} \mathrm{O}$ atmosphere (Supplementary Figure S20). Such an increase in the protonic contribution is unusual, since the proton conduction component in oxides generally decreases upon increasing the temperature due to thermal dehydration. The reduction in the number of higher coordination environments and subsequent increase in the concentration of lower coordination geometries must facilitate the ionic transport in the palmierite-like layers. It is well known that isolated tetrahedral/lower coordination moieties provide favourable and more dynamic environments for oxygen migration ${ }^{10,11,12}$. The presence of a flexible average tetrahedral environment facilitates proton mobility in $\mathrm{Ba}_{7} \mathrm{Nb}_{4} \mathrm{MoO}_{20}$, as previously reported

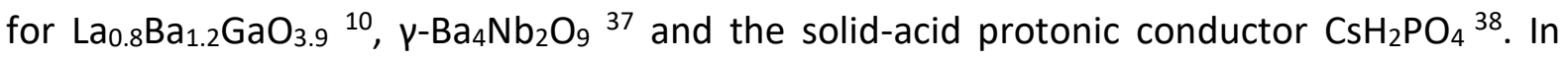
contrast the related phase $\mathrm{Ba}_{3} \mathrm{NbMoO}_{8.5}$ which contains predominantly higher coordination geometries in the palmierite layer does not exhibit proton conductivity ${ }^{29,} 33$ (Supplementary Figure S21). In addition, the change in crystal structure results in a considerable reduction in the shortest $01-01$ distance above $300{ }^{\circ} \mathrm{C}$ (from $\sim 3.12 \AA$ to $\sim 2.85 \AA$, Supplementary Figure S29), which may further enhance proton migration. A decrease of the enthalpy of proton diffusion has been found to coincide with a reduction in the inter-tetrahedral oxygen separation in the proton conductor $\mathrm{LaNbO}_{4}{ }^{39}$. Shorter O-O separations at the barrier state also facilitates proton transfer in gallium based oxides and acceptor doped perovskites ${ }^{10,13}$. Thermogravimetric analysis conducted by cooling $\mathrm{Ba}_{7} \mathrm{Nb}_{4} \mathrm{MoO}_{20}$ in equilibrium isotherms under humidified air $\left(\mathrm{pH}_{2} \mathrm{O} \sim 0.021 \mathrm{~atm}\right)$ evidences a uniform water uptake (Figure 5a); the swift mass response to the temperature steps implies rapid migration of the ionic defects ${ }^{18}$. At room temperature, the weight increase corresponds to $\sim 0.80 \mathrm{H}_{2} \mathrm{O}$ molecules per formula 
unit (resulting in a volume increase of about 0.6\%, (Supplementary Figure S31)), in accordance with the number of water molecules lost on dehydration of the sample. The obtained number of molecules of water is close to the theoretical solubility limit of one water molecule per formula unit, corresponding with one oxygen vacancy per formula unit of $\mathrm{Ba}_{7} \mathrm{Nb}_{4} \mathrm{MoO}_{20}$. Figure $5 b$ presents the thermal variation of the equilibrium constant of $\mathrm{Ba}_{7} \mathrm{Nb}_{4} \mathrm{MoO}_{20}$. For $\mathrm{T}<$ $300{ }^{\circ} \mathrm{C}$ the hydration enthalpy is $\Delta H^{0}=-17 \mathrm{~kJ} \mathrm{~mol}^{-1}$ and the hydration entropy $\Delta S^{0}=-20 \mathrm{~J} \mathrm{~K}^{-1}$ $\mathrm{mol}^{-1}$; above $300{ }^{\circ} \mathrm{C}$ there is a gradual change in slope with $\Delta H^{0}=-74 \mathrm{~kJ} \mathrm{~mol}^{-1}$ and $\Delta S^{0}=-83 \mathrm{~J}$ $\mathrm{K}^{-1} \mathrm{~mol}^{-1}$ at high temperatures, similar to other prominent proton conductors (Figure 5b) ${ }^{13,40}$ (Supplementary Information S7 gives information on the calculation). The nonlinear behaviour of $K_{\mathrm{w}}$ highlights two different hydration regimes (effects from hole concentrations and incomplete equilibration can clearly be ruled out ${ }^{40}$ ). Non-Arrhenius behaviour has been reported in the triple conducting double-perovskite $\operatorname{PrBa}_{0.5} \mathrm{Sr}_{0.5} \mathrm{Co}_{1.5} \mathrm{Fe}_{0.5} \mathrm{O}_{5+\delta}$ as a result of the changing hydration state with temperature ${ }^{18}$. In $\mathrm{Ba}_{2} \ln _{2} \mathrm{O}_{5}$ materials the non-linear behaviour is associated with the multi-step nature of the hydration/dehydration process, involving structural transitions and different proton sites ${ }^{41,42}$. In $\mathrm{Ba}_{7} \mathrm{Nb}_{4} \mathrm{MoO}_{20}$, hydration is correlated with the change in $01 / 02$ occupancies. Hydration becomes more favourable $\left(\Delta H^{0}\right.$ more exothermic) above $300{ }^{\circ} \mathrm{C}$, with the structural rearrangement of the oxygen/vacancy distribution most likely facilitating the water uptake. $\mathrm{Ba}_{3} \mathrm{NbMoO}_{8.5}$, which contains a larger concentration of octahedral units, is generally less prone to uptake water, but shows similar behaviour to $\mathrm{Ba}_{7} \mathrm{Nb}_{4} \mathrm{MoO}_{20}$, with the hydration becoming more favourable after the transition to predominately lower coordination above $300{ }^{\circ} \mathrm{C}$. The entropy values suggest a small entropic penalty in hydrating the hexagonal derivative and correlates with the high proton content, as proposed for the double-perovskite $\mathrm{PrBa}_{0.5} \mathrm{Sr}_{0.5} \mathrm{Co}_{1.5} \mathrm{Fe}_{0.5} \mathrm{O}_{5+\delta}{ }^{18}$. 

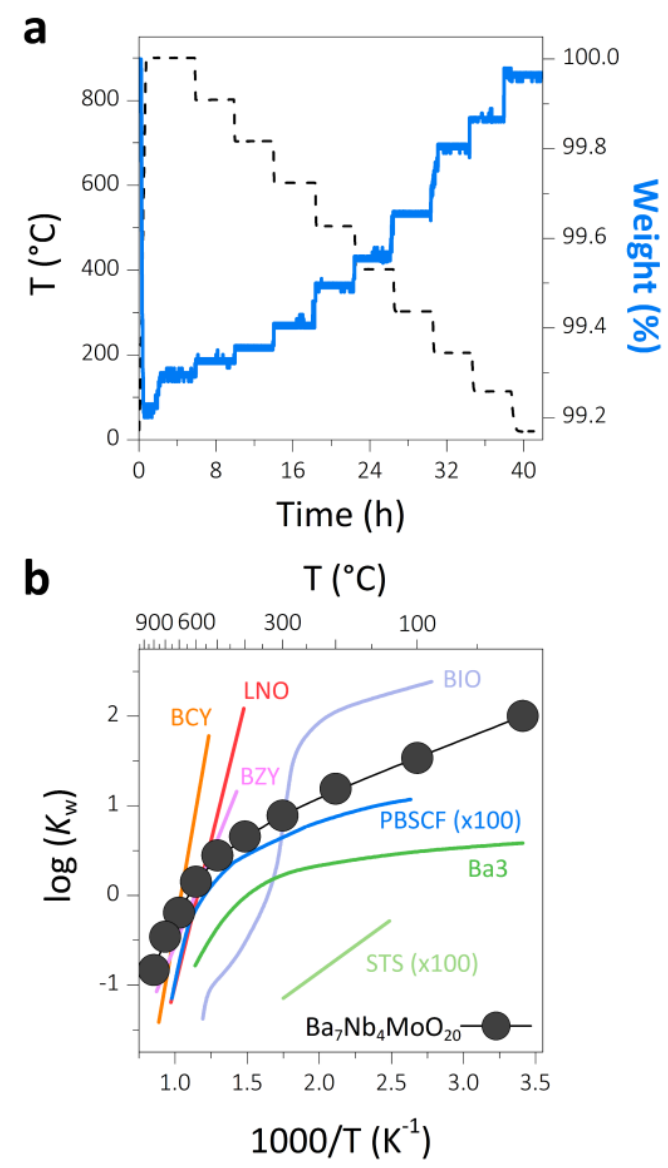

Figure 5. Hydration of $\mathrm{Ba}_{7} \mathrm{Nb}_{4} \mathrm{MoO}_{20}$. a Water uptake of $\mathrm{Ba}_{7} \mathrm{Nb}_{4} \mathrm{MoO}_{20}$ measured by equilibrium isotherms with thermogravimetric analysis under humidified air $\left(\mathrm{pH}_{2} \mathrm{O} \sim 0.021\right.$ atm). b Equilibrium constant for the water incorporation reaction, showing nonlinear behaviour associated with two different hydration regimes. The equilibrium constants of other proton conductors are shown for comparison: $\mathrm{BaCe}_{0.9} \mathrm{Y}_{0.1} \mathrm{O}_{3-\delta}(\mathrm{BCY}), \mathrm{BaZr}_{0.9} \mathrm{Y}_{0.1} \mathrm{O}_{3-\delta}$ (BZY), $\mathrm{SrTi}_{0.92} \mathrm{Sc}_{0.02} \mathrm{O}_{3-\delta}$ (STS) (all from ref. 13), $\mathrm{La}_{0.99} \mathrm{Ca}_{0.01} \mathrm{NbO}_{4}$ (LNO) (extrapolated from enthalpy and entropy values reported in ref. 16), $\mathrm{Ba}_{1.8} \mathrm{La}_{0.2} \mathrm{In}_{2} \mathrm{O}_{5.1}$ (BIO) (ref. 41), and tripleconducting $\mathrm{PrBa}_{0.5} \mathrm{Sr}_{0.5} \mathrm{Co}_{1.5} \mathrm{Fe}_{0.5} \mathrm{O}_{5+\delta}$ (PBSCF) (ref. 18).

Proton conduction under humidified atmospheres has been reported in a few hexagonal perovskite oxides, although these systems present low conductivity values and predominant electronic $p$ - and/or $n$-type contributions $37,43,44,45,46 . \mathrm{Ba}_{7} \mathrm{Nb}_{4} \mathrm{MoO}_{20}$ is the first hexagonal derivative to show dual-ion conduction, with significant oxide ion conduction in dry oxidising/reducing conditions and high proton conductivity in humidified atmospheres. Conversely, most proton conductors exhibit $p$-type electronic conductivity at high $\mathrm{pO}_{2}$ values and/or under dry conditions ${ }^{14,16,25,47}$. The proton conductivity of $\mathrm{Ba}_{7} \mathrm{Nb}_{4} \mathrm{MoO}_{20}$ is also the highest observed in an oxide crystallising with a structure different from the ideal cubic 
perovskite. The high ionic conductivity and the excellent chemical and electrical stability (Supplementary Figure S25) make $\mathrm{Ba}_{7} \mathrm{Nb}_{4} \mathrm{MoO}_{20}$ particularly interesting for applications in both SOFC and PCFC systems running on hydrocarbon fuels, and for the production of dualion electrolyte systems.

The unique ionic conduction properties of $\mathrm{Ba}_{7} \mathrm{Nb}_{4} \mathrm{MoO}_{20}$ are associated with the disorder within the crystal structure. As analogously observed in the hexagonal perovskite derivative $\mathrm{Ba}_{3} \mathrm{NbMO}_{8.5}{ }^{34,48}$, the structure exhibits considerable disorder of the oxide ions and of the cation vacancies. This disorder creates variable and dynamic $\mathrm{MO}_{\mathrm{x}}$ configurations accommodating the intrinsic anion vacancies and the protonic defects in $\mathrm{Ba}_{7} \mathrm{Nb}_{4} \mathrm{MoO}_{20}$, also assisting the ionic migration. The ionic conductivity in these hybrid systems is correlated with the relative average concentration of lower and higher coordination environments along the palmierite-like layers $30,33,48$, indicating that the ionic conductivity properties might be tailored by insertion of cations with preference for lower coordination geometries ${ }^{49}$. Other derivatives able to support ionic conduction could potentially be found among the members of the pseudo-ternary phase diagram of the Ba-Nb-Mo-O system (Supplementary Figure S4). In addition, the ease of substitution of the $M$ cations in these hexagonal derivatives could also lead to the generation of different hexagonal polytypes with diverse electrical properties ${ }^{30}$, 37, 43 . The results presented here suggest that other layered cation-deficient hexagonal perovskites might support similar cation and anion disordered environments, favourable for significant ionic conduction. 


\section{References}

1 Steele, B. C. H. \& Heinzel, A. Materials for fuel-cell technologies. Nature 414, 345-352 (2001).

2 Duan, C. et al. Readily processed protonic ceramic fuel cells with high performance at low temperatures. Science 349, 1321-1326 (2015).

3 Wachsman, E. D. \& Lee, K. T. Lowering the temperature of solid oxide fuel cells. Science 334, 935-939 (2011).

4 Jacobson, A. J. Materials for solid oxide fuel cells. Chem. Mater. 22, 660-674 (2010).

5 Abraham, F., Boivin, J. C., Mairesse, G. \& Nowogrocki, G. The BIMEVOX series: a new family of high performances oxide ion conductors. Solid State Ionics 40-41, 934-937 (1990).

6 Huang, K., Tichy, R. S. \& Goodenough, J. B. Superior perovskite oxide-ion conductor; strontium- and magnesium-doped $\mathrm{LaGaO}_{3}: \mathrm{I}$, phase relationships and electrical properties. $J$ Am. Ceram. Soc. 81, 2565-2575 (1998).

$7 \mathrm{Li}, \mathrm{M}$. et al. A family of oxide ion conductors based on the ferroelectric perovskite $\mathrm{Na}_{0.5} \mathrm{Bi}_{0.5} \mathrm{TiO}_{3}$. Nature Materials 13, 31-35 (2013).

8 Shin, J. F., Orera, A., Apperley, D. C. \& Slater, P. R. Oxyanion doping strategies to enhance the ionic conductivity in $\mathrm{Ba}_{2} \ln _{2} \mathrm{O}_{5}$. J. Mater. Chem. 21, 874-879 (2011).

9 Kendrick, E., Islam, M. S. \& Slater, P. R. Developing apatites for solid oxide fuel cells: insight into structural, transport and doping properties. J. Mater. Chem. 17, 3104-3111 (2007).

10 Kendrick, E., Kendrick, J., Knight, K. S., Islam, M. S. \& Slater, P. R. Cooperative mechanisms of fast-ion conduction in gallium-based oxides with tetrahedral moieties. Nature Materials 6, 871-875 (2007).

11 Kuang, X. et al. Interstitial oxide ion conductivity in the layered tetrahedral network melilite structure. Nature Materials 7, 498-504 (2008).

12 Yang, X. et al. Cooperative mechanisms of oxygen vacancy stabilization and migration in the isolated tetrahedral anion Scheelite structure. Nature Communications 9, 4484 (2018).

13 Kreuer, K. D., Proton-conducting oxides. Annu. Rev. Mater. Res. 33, 333-359 (2003).

14 Fabbri, E., Pergolesi, D. \& Traversa, E. Materials challenges toward proton-conducting oxide fuel cells: a critical review. Chem. Soc. Rev. 39, 4355-4369 (2010).

15 Zhang, G. B. \& Smyth, D. M. Protonic conduction in $\mathrm{Ba}_{2} \ln _{2} \mathrm{O}_{5}$. Solid State lonics 82, 153-160 (1995). 
16 Haugsrud, R. \& Norby, T. Proton conduction in rare-earth ortho-niobates and orthotantalates. Nature Materials 5, 193-196 (2006).

17 Bae, K. et al. Demonstrating the potential of yttrium-doped barium zirconate electrolyte for high-performance fuel cells. Nature Communications 8, 14553 (2017).

18 Choi, S.et al. Exceptional power density and stability at intermediate temperatures in protonic ceramic fuel cells. Nat. Energy 3, 202-210 (2018).

19 Zakowsky, N., Williamson, S. \& Irvine, J. T. S. Elaboration of $\mathrm{CO}_{2}$ tolerance limits of $\mathrm{BaCe}_{0.9} \mathrm{Y}_{0.1} \mathrm{O}_{3-\delta}$ electrolytes for fuel cells and other applications. Solid State lonics 176, 30193026 (2005).

20 Bhide, S. V. \& Virkar, A. V. Stability of $\mathrm{BaCeO}_{3}-\mathrm{Based}$ proton conductors in water-containing atmospheres. Journal of The Electrochemical Society 146, 2038-2044 (1999).

21 Sažinas, R., Bernuy-López, C., Einarsrud, M. \& Grande, T. Effect of $\mathrm{CO}_{2}$ exposure on the chemical stability and mechanical properties of $\mathrm{BaZrO}_{3}$-ceramics. J. Am. Ceram. Soc. 99, 36853695 (2016).

22 Jankovic, J., Wilkinson, D. P. \& Hui, R. Proton conductivity and stability of $\mathrm{Ba}_{2} \ln _{2} \mathrm{O}_{5}$ in hydrogen containing atmospheres. Journal of The Electrochemical Society 158, B61-B68 (2011).

23 Shin, J. F. \& Slater, P. R. Enhanced $\mathrm{CO}_{2}$ stability of oxyanion doped $\mathrm{Ba}_{2} \ln _{2} \mathrm{O}_{5}$ systems codoped with La, Zr. Journal of Power Sources 196, 8539-8543 (2011).

24 D'Epifanio, A., Fabbri, E., Di Bartolomeo, E., Licoccia, S. \& Traversa, E. Design of $\mathrm{BaZr}_{0.8} \mathrm{Y}_{0.2} \mathrm{O}_{3-\delta}$ protonic conductor to improve the electrochemical performance in intermediate temperature solid oxide fuel cells (IT-SOFCs). Fuel Cells 8, 69-76 (2008).

25 Yang, L., Wang, S., Blinn, K., Liu, M., Cheng, Z. \& Liu, M. Enhanced sulphur and coking tolerance of a mixed ion conductor for SOFCs: $\mathrm{BaZr}_{0.1} \mathrm{Ce}_{0.7} \mathrm{Y}_{0.2-\mathrm{x}} \mathrm{Yb}_{\mathrm{x}} \mathrm{O}_{3-\delta}$. Science 326, 126-129 (2009).

26 Zhou, C., Sunarso, J., Song, Y., Dai, J., Zhang, J., Gu, B., Zhou, W. \& Shao, Z. New reducedtemperature ceramic fuel cells with dual-ion conducting electrolyte and triple-conducting double perovskite cathode. J. Mater. Chem. A 7, 13265-13274 (2019).

27 Katz, L. \& Ward, R. Structure Relations in Mixed Metal Oxides. Inorg. Chem. 3, 205-211 (1964). 
28 Darriet, J. \& Subramanian, M. A. Structural relationships between compounds based on the stacking of mixed layers related to hexagonal perovskite-type structures. J. Mater. Chem. 5, 543-552 (1995).

29 Fop, S. et al. Oxide ion conductivity in the hexagonal perovskite derivative $\mathrm{Ba}_{3} \mathrm{MoNbO}_{8.5}$. J. Am. Chem. Soc. 138, 16764-16769 (2016).

30 McCombie, K. S. et al. The crystal structure and electrical properties of the oxide ion conductor $\mathrm{Ba}_{3} \mathrm{WNbO}_{8.5}$. J. Mater. Chem. A 6, 5290-5295 (2018).

31 Garcia-González, E., Parras, M. \& González-Calbet, J. M. Crystal structure of an unusual polytype: 7H-Ba7Nb4${ }_{4} \mathrm{MoO}_{20}$. Chem. Mater. 11, 433-437 (1999).

32 Irvine, J. T. S., Sinclair, D. C. \& West, A. R. Electroceramics: characterization by impedance spectroscopy. Adv Mater 2, 132-138 (1990).

33 Chambers, M. S. et al. Hexagonal perovskite related oxide ion conductor $\mathrm{Ba}_{3} \mathrm{NbMoO}_{8.5}$ : phase transition, temperature evolution of the local structure and properties. J. Mater. Chem. A, 7, 25503-25510 (2019).

34 Auckett, J. E., Milton, K. L. \& Evans, I. R. Cation distributions and anion disorder in $\mathrm{Ba}_{3} \mathrm{NbMO}_{8.5}(\mathrm{M}=\mathrm{Mo}, \mathrm{W})$ materials: implications for oxide ion conductivity. Chem. Mater. 31, 1715-1719 (2019).

35 Yashima, M. et al. Direct evidence for two-dimensional oxide-ion diffusion in the hexagonal

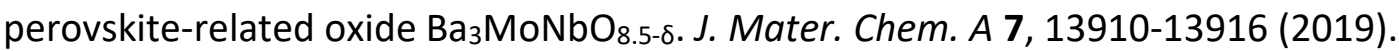

36 Islam, M. S. Computer modelling of defects and transport in perovskite oxides. Solid State lonics 154-155, 75-85 (2002).

37 Wind, J., Mole, R. A., Yu, D., Avdeev, M. \& Ling, C. D. Hydration mechanisms and proton conduction in the mixed ionic-electronic conductors $\mathrm{Ba}_{4} \mathrm{Nb}_{2} \mathrm{O}_{9}$ and $\mathrm{Ba}_{4} \mathrm{Ta}_{2} \mathrm{O}_{9}$. Chem. Mater. 30, 4949-4958 (2018).

38 Kim, G., Griffin, J. M., Blanc, F., Haile, S. M. \& Grey, C. P. Characterization of the dynamics in the protonic conductor $\mathrm{CsH}_{2} \mathrm{PO}_{4}$ by ${ }^{17} \mathrm{O}$ solid-state NMR spectroscopy and first-principles calculations: correlating phosphate and protonic motion. J. Am. Chem. Soc. 137, 3867-3876 (2015).

39 Huse, M. et al. Neutron diffraction study of the monoclinic to tetragonal structural transition in $\mathrm{LaNbO}_{4}$ and its relation to proton mobility. Journal of Solid State Chemistry 187, 27-34 (2012). 
40 Yamazaki, Y., Babilo, P. \& Haile, S. M. Defect chemistry of yttrium-doped barium zirconate: a thermodynamic analysis of water uptake. Chem. Mater. 20, 6352-6357 (2008).

41 Noirault, S. et al. Water incorportation into the $\left(\mathrm{Ba}_{1-\mathrm{x}} \mathrm{La}_{\mathrm{x}}\right)_{2} \ln _{2} \mathrm{O}_{5+\mathrm{x} \square 1-\mathrm{x}}(0 \leq \mathrm{x} \leq 0.6)$ system. Solid State Ionics 178, 1353-1359 (2007).

42 Bielecki, J., Parker, S. F., Mazzei, L., Börjesson, L. \& Karlsson, M. Structure and dehydration mechanism of the proton conducting oxide $\mathrm{Ba}_{2} \ln _{2} \mathrm{O}_{5}\left(\mathrm{H}_{2} \mathrm{O}\right)_{x}$. J. Mater. Chem. A 4, 1224-1232 (2016).

43 Dunstan, M. T. et al. Phase behavior and mixed ionic-electronic conductivity of $\mathrm{Ba}_{4} \mathrm{Sb}_{2} \mathrm{O}_{9}$. Solid State Ionics 235, 1-7 (2013).

44 Rahman, S. M. H. et al. Proton conductivity of hexagonal and cubic $\mathrm{BaT}_{1-\mathrm{x}} \mathrm{Sc}_{x} \mathrm{O}_{3-\delta}(0.1 \leq \mathrm{x} \leq$ 0.8). Dalton Trans. 43, 15055-15064 (2014).

45 Tabacaru, C. et al. Protonic and electronic defects in the 12R-type hexagonal perovskite $\mathrm{Sr}_{3} \mathrm{LaNb}_{3} \mathrm{O}_{12}$. Solid State lonics 253, 239-246 (2013).

46 Kultz. Unti, L. F., Grzebielucka, E. C., Antonio Chinelatto, A. S., Mather, G. C. \& Chinelatto, A. L. Synthesis and electrical characterization of $\mathrm{Ba}_{5} \mathrm{Nb}_{4} \mathrm{O}_{15}$ and $\mathrm{Ba}_{5} \mathrm{Nb}_{3.9} \mathrm{M}_{0.1} \mathrm{O}_{(15-\delta)}(\mathrm{M}=\mathrm{Ti}, \mathrm{Zr})$ hexagonal perovskites. Ceramics International 45, 5087-5092 (2019).

47 Nomura, K. \& Kageyama, H. Transport properties of $\mathrm{Ba}\left(\mathrm{Zr}_{0.8} \mathrm{Y}_{0.2}\right) \mathrm{O}_{3-\delta}$ perovskite. Solid State Ionics 178, 661-665 (2007).

48 Fop, S. et al. Investigation of the relationship between the structure and conductivity of the novel oxide ionic conductor $\mathrm{Ba}_{3} \mathrm{MoNbO}_{8.5}$. Chem. Mater. 29, 4146-4152 (2017).

49 Fop, S., McCombie, K. S., Wildman, E. J., Skakle, J. M. S. \& Mclaughlin, A. C. Hexagonal perovskite derivatives: a new direction in the design of oxide ion conducting materials. Chem. Commun. 55, 2127-2137 (2019). 


\section{Methods}

Samples of $\mathrm{Ba}_{7} \mathrm{Nb}_{4} \mathrm{MoO}_{20}$ were prepared by the solid-state reaction method via successive heatings at $1050^{\circ} \mathrm{C}$ for $48 \mathrm{~h}$. Dense ceramic pellets ( 95\% theoretical density) were obtained by sintering the powder at $1200{ }^{\circ} \mathrm{C}$ for $5 \mathrm{~h}$, followed by a dwell at $1050{ }^{\circ} \mathrm{C}$ for $48 \mathrm{~h}$. Sintering at $1200{ }^{\circ} \mathrm{C}$ is required to obtain dense pellet samples, although heating of $\mathrm{Ba}_{7} \mathrm{Nb}_{4} \mathrm{MoO}_{20}$ above $1100{ }^{\circ} \mathrm{C}$ leads to the formation of small $(<1 \%)$ impurity phases of $\mathrm{Ba}_{3} \mathrm{NbMoO}_{8.5}$ and $\mathrm{Ba}_{5} \mathrm{Nb}_{4} \mathrm{O}_{15}$. However, sintering at $1200^{\circ} \mathrm{C}$ followed by subsequent annealing at $1050^{\circ} \mathrm{C}$ results in phase pure dense materials, as confirmed by X-ray diffraction on both the powder and pellet samples (Supplementary Figure S8). Phase purity and stability was analysed by X-ray diffraction (XRD). Scanning electron microscopy (SEM) and energy-dispersive X-ray spectroscopy (EDS) were employed for examining composition and ceramic microstructure. Impedance spectroscopy measurements were recorded on a dense $\mathrm{Ba}_{7} \mathrm{Nb}_{4} \mathrm{MoO}_{20}$ pellet sample ( $10 \mathrm{~mm}$ diameter and $\sim 1 \mathrm{~mm}$ thickness) with a Solartron 1260 impedance analyser in the frequency range $0.1 \mathrm{~Hz}-1 \mathrm{MHz}$ with an applied alternating voltage of $0.1 \mathrm{~V}$. Pt electrodes were painted on both sides of the pellet using a Pt-paste subsequently cured at $900{ }^{\circ} \mathrm{C}$. Data were recorded upon cooling from $800{ }^{\circ} \mathrm{C}$ in a sealed tube furnace under flow of various gases, measuring every $\sim 15{ }^{\circ} \mathrm{C}$ and allowing 2 hours of equilibration at each temperature step. Dry atmospheres were obtained by flowing the employed gas through a column of a commercial desiccant (Drierite) $\left(\mathrm{pH}_{2} \mathrm{O}<10^{-4} \mathrm{~atm}\right)$, while for the humidified atmospheres (i.e. air $+\mathrm{H}_{2} \mathrm{O}$ ) the gas was bubbled through a water-filled Dreschel bottle at ambient temperature $\left(\mathrm{pH}_{2} \mathrm{O} \sim 0.021 \mathrm{~atm}\right)$. Oxygen-ion transport measurements were performed on a similarly prepared dense $\mathrm{Ba}_{7} \mathrm{Nb}_{4} \mathrm{MoO}_{20}$ sample using a concentration cell. To assure gas tightness, sample was cemented on the holder. Open circuit voltages were recorded on cooling from $800{ }^{\circ} \mathrm{C}$ to $500{ }^{\circ} \mathrm{C}$ every $100^{\circ} \mathrm{C}$, leaving enough time for the sample to reach equilibrium with the surrounding atmosphere, using a Solartron 1287 electrochemical interface. In all the measurements, one side of the pellet was exposed to a flow of dry air and the other to dry flows of oxygen or $5 \% \mathrm{H}_{2}$ (in Ar). The conductivity dependence on the oxygen partial pressure $\left(\mathrm{OO}_{2}\right)$ of a porous pellet of $\mathrm{Ba}_{7} \mathrm{Nb}_{4} \mathrm{MoO}_{20}$ with $70 \%$ of the theoretical density was recorded at $800^{\circ} \mathrm{C}, 700^{\circ} \mathrm{C}$ and $600^{\circ} \mathrm{C}$, over a $\mathrm{pO}_{2}$ range of $10^{-25}-1 \mathrm{~atm}$ (monitored with a YSZ sensor placed close to the sample). The $\mathrm{pO}_{2}$ range was controlled by purging the sample chamber with different gases $\left(\mathrm{O}_{2}, \mathrm{~N}_{2}\right.$ or $5 \% \mathrm{H}_{2}$ (in $\left.\mathrm{Ar}\right)$ ) 
regulated by solenoid pulse valves using feedback from the measured $p \mathrm{O}_{2}$ to hold the partial pressure of oxygen steady. The conductivity was measured using a Keithley 182 Sensitive Digital Voltmeter with a four-electrode configuration.

Variable temperature neutron diffraction data in the temperature range $50{ }^{\circ} \mathrm{C}$ to $700{ }^{\circ} \mathrm{C}$ were collected on the high-resolution powder diffractometer D2B at the Institut Laue-Langevin (ILL) in Grenoble, France. A sample of $5 \mathrm{~g}$ of $\mathrm{Ba}_{7} \mathrm{Nb}_{4} \mathrm{MoO}_{20}$ was inserted in an open quartz tube and heated up to the desired temperatures. Data were collected at $\lambda=1.59432 \AA$ with a collection time of $\sim 3$ hours for each temperature step.

Thermogravimetric analysis on a crushed $\mathrm{Ba}_{7} \mathrm{Nb}_{4} \mathrm{MoO}_{20}$ pellet was performed using a Stanton Redcroft 780 thermal analyser. The sample was heated at $150{ }^{\circ} \mathrm{C}$ for $10 \mathrm{~h}$ prior the analysis in order to remove any adsorbed surface water. $\mathrm{Ba}_{7} \mathrm{Nb}_{4} \mathrm{MoO}_{20}$ was heated to $900^{\circ} \mathrm{C}$ at $20^{\circ} \mathrm{C} / \mathrm{min}$ in dry air $\left(p \mathrm{H}_{2} \mathrm{O}<10^{-4} \mathrm{~atm}\right)$ and held here for an hour; this step established a dry reference state. The sample gas was then saturated with water $\left(\mathrm{pH}_{2} \mathrm{O} \sim 0.021 \mathrm{~atm}\right)$ and the weight increase was recorded upon cooling in equilibrium isotherms. Data were collected every $100{ }^{\circ} \mathrm{C}$ from $900{ }^{\circ} \mathrm{C}$ to room temperature, with 4 hours stabilisation time at each temperature to allow the sample to reach equilibrium. The sample weight became constant well within two hours at all of the temperatures. 


\section{Acknowledgements}

This research was supported by the Leverhulme trust and EPSRC (MISE). We also acknowledge STFC-GB for provision of beamtime at the ILL.

\section{Author Contributions}

A.C.M. and S.F. designed the study. S.F. performed the synthesis and electrical characterisation of $\mathrm{Ba}_{7} \mathrm{Nb}_{4} \mathrm{MoO}_{20}$ and analysed the data along with K.S. and E.J.W. The transport and $\mathrm{pO}_{2}$ measurements were performed at the University of St. Andrews by S.F., P.A.C. and C.S. with guidance from J.T.S.I. The structural characterisation was performed by S.F. and K.M. with guidance from A.C.M, E.W., J.M.S.S. and C.R. S.F. performed the thermogravimetric measurements and analysed the results. A.C.M. and S.F. wrote the manuscript with E.W. A.C.M. directed the project.

\section{Author Information}

Correspondence and requests for materials should be addressed to A.C.M. (email: a.c.mclaughlin@abdn.ac.uk) or S.F. (email: sacha.fop1@abdn.ac.uk).

\section{Additional Information}

Competing Interests Statement The authors declare that they have no competing financial interests. 